\title{
The Barometer of Sustainability as a Monitoring Tool of the Sustainable Development Process in Ribeirão Preto, Brazil
}

\author{
André Cavalcante da Silva Batalhão ${ }^{1,2}$, Denílson Teixeira ${ }^{2}$ and Emiliano Lôbo de Godoi ${ }^{2}$ \\ 1. CENSE-Center of Environmental and Sustainability Research, Faculty of Sciences and Technology, New University of Lisbon, \\ Caparica 2829516, Portugal \\ 2. School of Civil and Environmental Engineering, Federal University of Goiás, Goiânia 74605220, Brazil
}

\begin{abstract}
The aim is to present and discuss the level of sustainability of Ribeirão Preto, Brazil based on Sustainability Indicators using the Barometer of Sustainability. The Barometer of Sustainability is a method of two-dimensional analysis which assesses the wellbeing in human and ecological dimensions of an equitable and systematic system, not leaving the data overlap, not masking the results and finding in a Wellbeing Index. The results showed that Ribeirão Preto is on intermediate level in relation to sustainable development with better performance in human dimensions. The themes of Soil and Biodiversity were considered unsustainable in the analysis of findings. This reveals that the city presents a greater concern with the socio-economic issues at the expense of environmental issues.
\end{abstract}

Key words: Sustainability Indicators, Barometer of Sustainability, wellbeing, Ribeirão Preto.

\section{Introduction}

The growing concern with natural resources, social impacts and technological evolution are determining factors in the search for a new development paradigm in which environmental issues can be expressed in an integrated environmental policy. In the 1970s and early 1980s, the conservation and preservation of natural resources and the role of the integrated man in the middle began to play a very important role in the discussion of the quality of life of the population [1]. Regardless of the objectives or the planned site, this strategy requires the specialization of a broadset of data that need to be compared, overlapping and holistically assessed.

Indicators directed to the monitoring of Sustainable Development can be defined as methodological tools that allow to transmit technical information in a

Corresponding author: André Cavalcante da Silva Batalhão, Ph.D. candidate, main research fields: environmental planning and management, Sustainability Indicators and Environmental Sciences. synthetic way, conserving the original meaning of the data and accepting depending on the studied object only the variables that best mirror the research objectives. These indicators quantify phenomena, events and complex realities with a relevant role in the decision-making processes for the direction of actions and also in the elaboration, monitoring and execution of public policies. When analyzing an indicator, the authors look at its current picture from the historical perspective by supporting the ability to project future trends and conditions to develop ways of tracking and measuring its behavior over time.

The main purpose of the indicators is to aggregate and quantify information so that its significance becomes more apparent. They simplify information about complex phenomena by trying to improve the communication process [2].

The evaluation tool chosen for the present research was the BS (Barometer of Sustainability) that allows understanding, evaluating and communicating society about the interactions between man and biosphere [3]. 
The methodology for building the BS is flexible architecture and is not composed of fixed indicators which allow the construction of Performance Scales that contains the ranges of degrees of sustainability and has comparative attributions. This methodology combines indicators of human well-being (social, economic and institutional) and ecological (biophysical) well-being that can be applied from the local to the global scale.

The aim was to analyze the effectiveness of the instrument Sustainability Barometer as a tool for monitoring the Sustainable Development process. The work also becomes important to expose the level of sustainability of the spatial clipping, in this case the city of Ribeirão Preto, generating analyzes of the themes covered by the research. Part of the challenge of this type of research is to define the indicators that can feed the instrument to bring robust and reliable results.

\section{Methodology}

2.1 Ribeirão Preto as Reference of Analysis: Characterization of the Study Area

The research area is the municipality of Ribeirão
Preto located northeast of the State of São Paulo, Brazil, $313 \mathrm{~km}$ from the capital São Paulo (Fig. 1). The total territorial area (urban and rural) of the locality is $650.96 \mathrm{~km}^{2}$ with a degree of urbanization of $99.72 \%$ and a population of 613,346 inhabitants [4]. The municipality of Ribeirão Preto is part of the UGRHI 4-Pardo (Water Resources Management Unit 4), which is composed of 23 municipalities and supplied by the Guarani Aquifer, the largest source of transboundary freshwater of the world [5].

Ribeirão Preto is the center of a region of high development indices in relation to the municipalities of Brazil and has as a positive point the diversification of its economy and the quality of life of the citizens. In 1856, the city took the impetus for development with the coffee plantations cultivated by the immigrants that counted on a ground of excellent quality known as ground-purple [6].

\subsection{Methodological Arrangements for Ttreatment and} Analysis of Data

The methodology adopted in this research is based on the Seven-Stage Cycle for the application of the Barometer of Sustainability with exploratory,

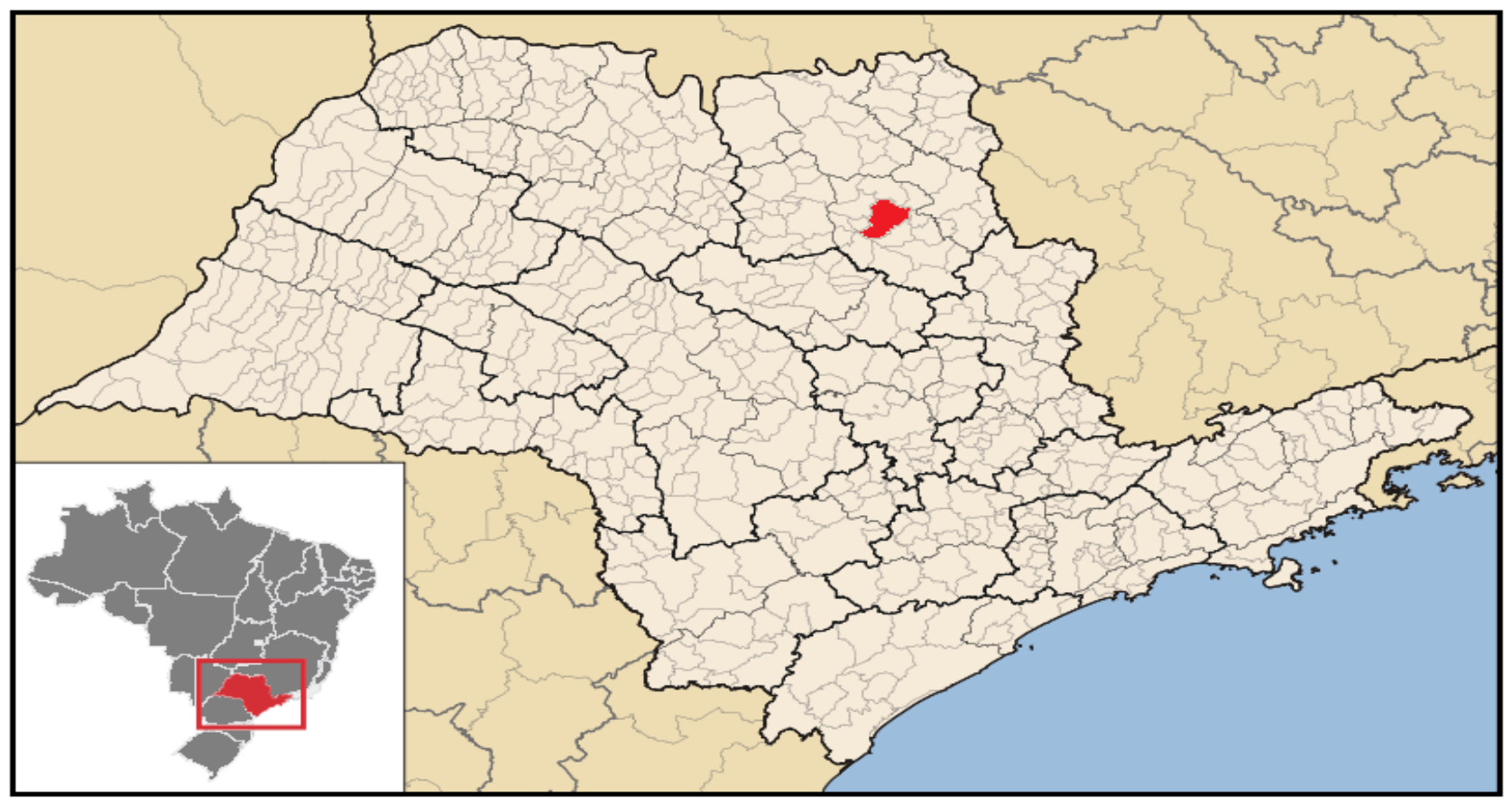

Fig. 1 Spatial area of the research. 
descriptive and field research characteristics from a delimited locality as the research universe (Ribeirão Preto, São Paulo, Brazil). Secondary data from reports and studies by researchers and institutional bodies related to the areas covered in the research were used.

The Seven Stages Cycle [7] bases the selection of the indicators to compose the Barometer of Sustainability with a hierarchical method composed of seven stages that helps to justify the importance and relevance of the indicators chosen in relation to the concept of Sustainable Development making perceptible deficiencies and needs of the physical space considered in the study. The seven stages are: (1) determination of the purpose of the evaluation; (2) definition of the system and goals; (3) clarification of performance dimensions and criteria; (4) choice of indicators and performance criteria; (5) data collection and mapping of indicators; (6) aggregation of indicators; and (7) review of results and assessment of implications.

An important step of the research is the transposition of the numerical value of the indicator to the Barometer of Sustainability Scale. It is done by means of a simple linear interpolation formula [8] that indicates the quality interval in which a certain indicator is allocated. The Eq. (1) shows the transposition of scales and the relationship between LDx (Local Development) and BSx (Scale in Barometer of Sustainability), whether the scale of Local Development increases or decreases. This is done in the operation of calculating the degree of the local indicator in the Sustainability Barometer Scale:

$$
\mathrm{BS}_{\mathrm{x}}=\left\{\left[\frac{\left(\mathrm{LD}_{\mathrm{A}}-\mathrm{LD}_{\mathrm{X}}\right)\left(\mathrm{BS}_{\mathrm{A}}-\mathrm{BS}_{\mathrm{P}}\right.}{\left(\mathrm{LD}_{\mathrm{A}}-\mathrm{LD}_{\mathrm{P}}\right.}\right](-1)\right\}+\mathrm{BS}_{\mathrm{A}}
$$

Read: $\mathrm{A}=$ previous boundary of the range containing $\mathrm{X}$. $\mathrm{P}=$ posterior boundary of the range containing X. After the transposition to the BS scale, the authors can visualize in which sector of sustainability the indicator fits.

BS is composed of five sectors that show the level of sustainability space. In Table 1 , it is possible to observe the initial and final point of each sector.

\subsection{Selection of Indicators to Compose the Barometer of Sustainability}

The selection of the indicators for the composition of the Barometer of Sustainability tool was made based on the consultation of sustainability indicators adopted by the Brazilian Institute of Geography and Statistics [9], adding other indicators that help the understanding of the chosen locality as a spatial cut. These indicators were elaborated the performance scales that are divided into five sectors, defined by values that represent conditions varying from unsustainable to sustainable. Such values are goals to be achieved or standards set globally, nationally or locally [10].

Each component dimension of the Barometer should be fed with a significant number of indicators to better inform the analysis of the results, but in each dimension and theme, the number of indicators is conditioned by the diversity of aspects present and the availability of data. As it can be seen, there still are important gaps arising from the absence of consistent

Table 1 The five sectors of the Barometer of Sustainability.

\begin{tabular}{llll}
\hline \multicolumn{2}{c}{ Points } & & \\
\hline Sector & Reach & Top & Definition \\
\hline Sustainable & $100-81$ & 100 & Desirable performance, goal achieved \\
Potentially sustainable & $80-61$ & 80 & Acceptable performance, goal almost achieved \\
Intermediate & $60-41$ & 60 & Transition performance \\
Potentially unsustainable & $40-21$ & 40 & Unwelcome performance \\
Unsustainable & $20-1$ & 20 & Unacceptable performance \\
Base & 0 & 0 & Base of the scale \\
\hline
\end{tabular}


Development Process in Ribeirão Preto, Brazil

Table 2 Common system of dimensions for the construction of the Barometer of Sustainability.

\begin{tabular}{|c|c|c|c|c|c|}
\hline \multicolumn{6}{|c|}{ Society } \\
\hline Health and population & Wealth & $\begin{array}{l}\begin{array}{l}\text { Knowledge and } \\
\text { culture }\end{array} \\
\end{array}$ & Community & Equity & Use of resources \\
\hline $\begin{array}{l}\text { Population growth, infant } \\
\text { mortality, immunization in } \\
\text { children up to one year of age, } \\
\text { immunization of infectious } \\
\text { diseases, low weight of children } \\
\text { under five years of age, families } \\
\text { accompanied by basic health } \\
\text { care, prenatal consultations, } \\
\text { maternal mortality, } \\
\text { Psychosocial Attention Center, } \\
\text { Beds for hospitalization, density } \\
\text { of residents per dormitory }\end{array}$ & $\begin{array}{l}\text { Unemployment } \\
\text {, average } \\
\text { monthly } \\
\text { income, GDP } \\
\text { per capita, } \\
\text { municipal } \\
\text { GDP, Gini } \\
\text { index }\end{array}$ & \begin{tabular}{l|} 
School \\
dropout, \\
literacy, IDEB \\
4th/5th grade, \\
IDEB 8th/9th \\
grade, access to \\
telephony \\
(mobile and \\
fixed), internet \\
access
\end{tabular} & $\begin{array}{l}\text { Mortality due } \\
\text { to homicide, } \\
\text { mortality due } \\
\text { to } \\
\text { transportation } \\
\text { accidents, } \\
\text { families served } \\
\text { by social } \\
\text { programs }\end{array}$ & $\begin{array}{l}\text { Women in } \\
\text { parliament, } \\
\text { women in the } \\
\text { formal labor } \\
\text { market }\end{array}$ & $\begin{array}{l}\text { Expenditure per capita with } \\
\text { solid waste, adequate final } \\
\text { disposal of collected waste, } \\
\text { sewage collected, treatment of } \\
\text { sewage collected, households } \\
\text { with garbage collection, } \\
\text { households with electric } \\
\text { lighting, households with water } \\
\text { supply, energy intensity, } \\
\text { recycling, garbage collection }\end{array}$ \\
\hline
\end{tabular}

Human Dimensions

\begin{tabular}{|l|l|l|l|}
\hline \multicolumn{3}{|c|}{ Ecosystem } \\
\hline Soil & Water & Air & Biodiversity \\
\hline $\begin{array}{l}\text { Total anthropic area, land use in } \\
\text { crops, pastures, forests and } \\
\text { livestock }\end{array}$ & $\begin{array}{l}\text { Water quality index, quality } \\
\text { index of protection of aquatic } \\
\text { life, indicator of potability of } \\
\text { groundwater }\end{array}$ & $\begin{array}{l}\text { Number of vehicles per capita, } \\
\text { tree cover, inhalable particles, } \\
\text { sulfur dioxide, nitrogen dioxide, } \\
\text { ozone }\end{array}$ & Natural vegetation \\
\hline
\end{tabular}

Ecological Dimensions

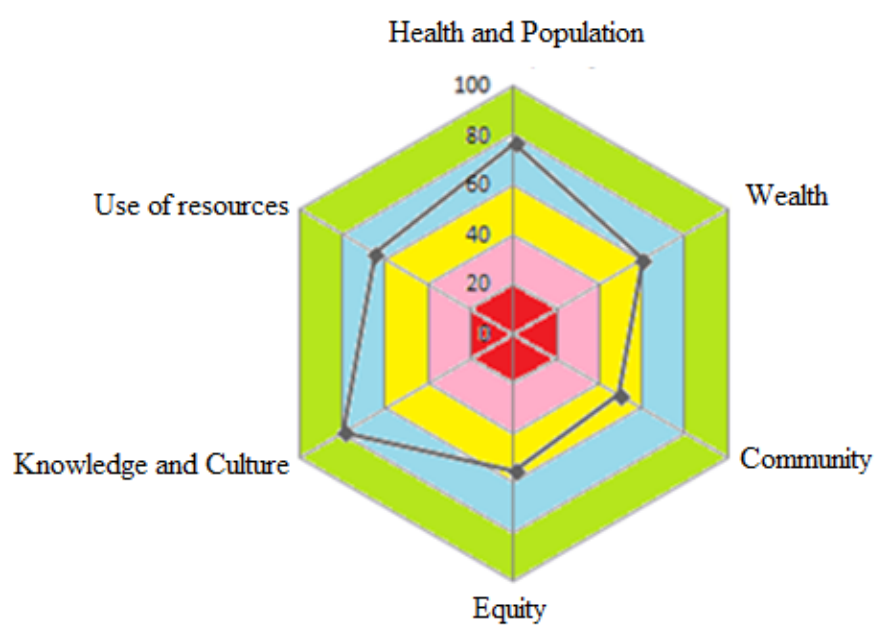

Human Subsystem

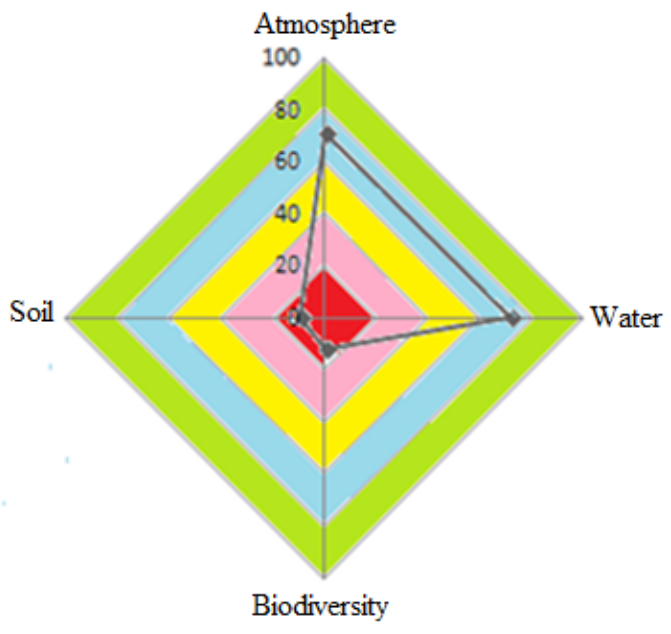

Ecological Subsystem

Fig. 2 Performance of themes in Human Dimensions and Ecological Dimensions.

national data for the setting of indicators [11]. Table 2

shows the composition of indicators relevant to each dimension.

\section{Results}

The calculation of the indicators in their respective themes generated in the Human and Ecological Subsystem six and four thematic indexes, respectively.
In Fig. 2, it is possible to observe the performance of the themes in each subsystem.

The system of WI (Wellbeing Index) is the arithmetic mean of the indexes found for the Subsystems that graphically illustrate the state of the system in relation to Sustainable Development. The value found for the Human Subsystem was 64 and the value for the Ecological Subsystem 41. The Ribeirão 
Preto WI was considered as an intermediary for sustainable development with a value of 52.5 . Prescott-Allen, R. [3], author of the book "Wellbeing of Nations", defines that in order to make an evaluation in terms of sustainability one must take into account the visual representation that the BS demonstrates. According to the author, the WI only serves to rank the systems considered. Fig. 3 marks the position of Ribeirão Preto in BS with the value of WI in relation to countries analyzed in the Wellbeing of Nations which presented the same WI of Ribeirão Preto. When the WI is dismembered the authors can perceive the HWI and the EWI which really gives us a broader view of the analysis done and allows a better understanding of the social and ecological issues of the systems. In Fig. 4, Ribeirão Preto is compared with South American countries. Among the countries analyzed the municipality would occupy the fifth place according to its WI, behind Guiana (57), Uruguay (56.5), Suriname (55) and Peru (53). The worst values in South America were with Brazil (40.5) and Paraguay (40.5).

The transgression of ecological rules to support a developmentalist ideology without ramifications in the principles of sustainability makes environmental imbalances more and more constant. Impacts or changes in human and ecological well-being are cross-border and should be incorporated into urban planning at various scales to better inform articulation mechanisms by generating information for a comparative analysis over time and re-evaluating the measures adopted in the process. Regional director plans can assist in the context of maintaining a more efficient level of management by providing the creation of a development model that dynamically identifies the system by observing its variables and interactions with other locations. Thereby, the preventive actions and integrated solutions provide healthiness not only for the locality, but also for the regional area.

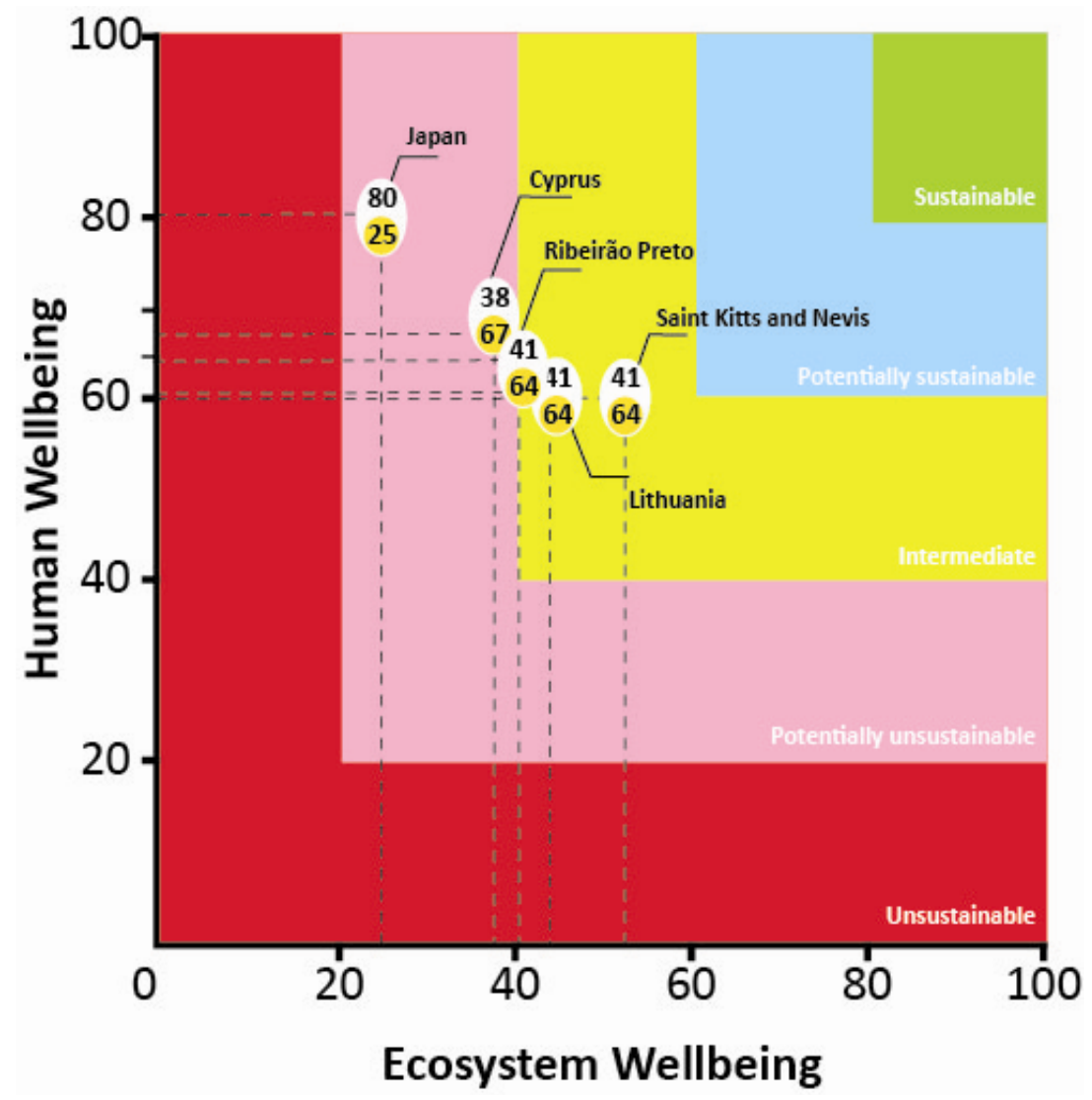

Fig. 3 Countries with the same WI of Ribeirão Preto. 


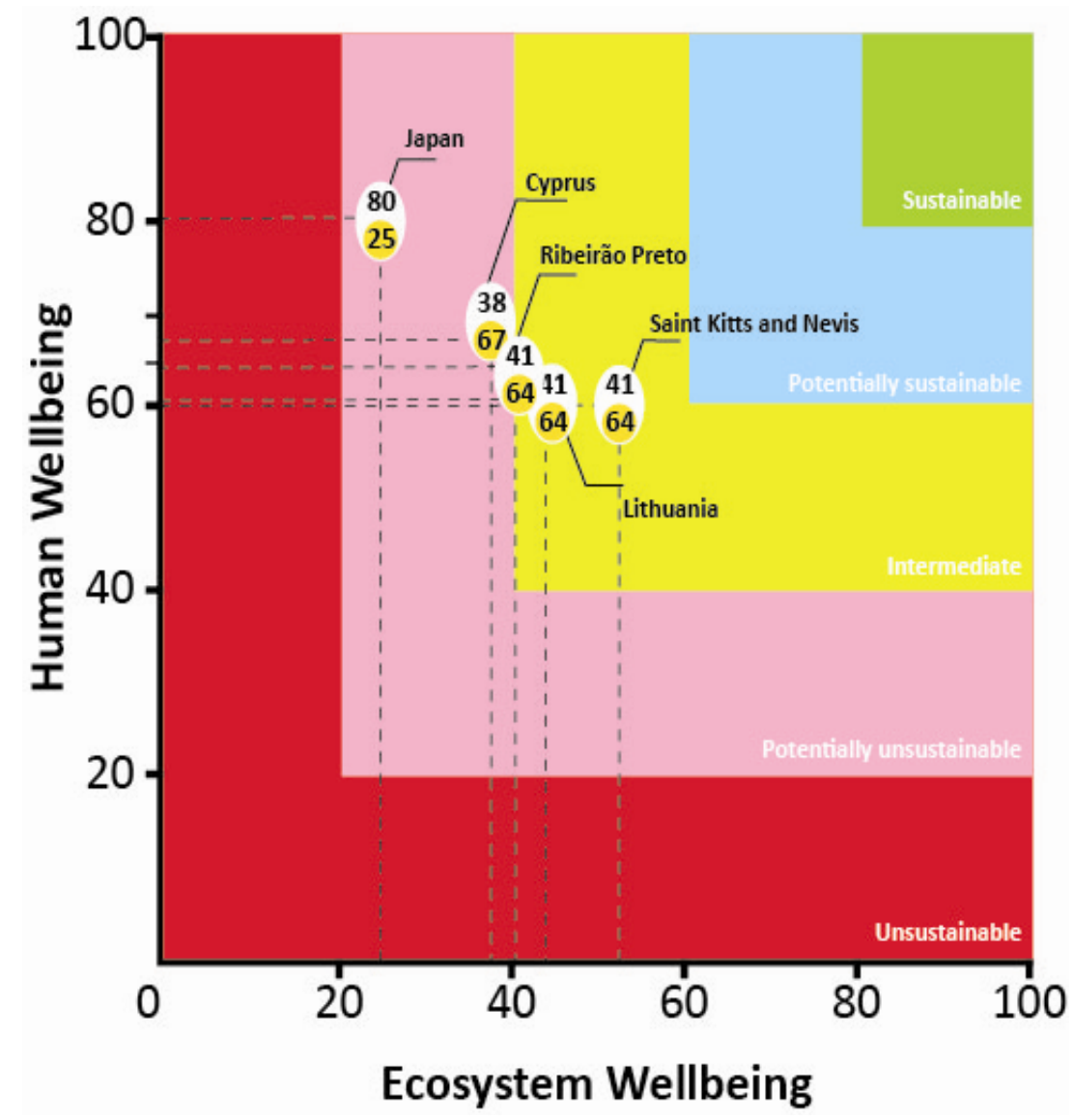

Fig. 4 Sustainability level of Ribeirão Preto and the countries of South America.

\section{Conclusion}

In this paper, the Barometer of Sustainability has proved to be an effective and scientifically proven evaluation tool with potential for incorporation into the decision making processes that allows for the systematic evaluation of environmental and human values at the local scale. For the management of risks associated with the environment and society, it is fundamental to search for the understanding of the new dynamics that occur on a large scale and in a fast way through normative, legal and social demands. The management way has a direct impact on the resolution of the environmental and social problems in which they need to integrate environmental and social variables into the short and long term objectives of governments. This movement should direct actions at the governmental level promoting local-global sustainability.

\section{References}

[1] Santos, R. F. 2004. "Environmental Planning: Theory and Practice.” São Paulo: Office of Texts: 184.

[2] Van Bellen, H. M. 2005. Sustainability Indicators: A Comparative Analysis. Rio de Janeiro: Fundação Getúlio Vargas.

[3] Prescott-Allen, R., and International Union for the Conservation of Nature and Natural Resources 2001. The Wellbeing of Nations: a Country-by-Country Index of Quality of Life and the Environment. Washington: Island Press.

[4] Foundation State System of Data Analysis. 2014. Information of Municipalities. Accessed October 12, 2015.

http://www.seade.gov.br/produtos/imp/index.php?page=t abela.

[5] Cetesb Environmental Company of the State of São Paulo. 2014. Water Quality. Accessed November 11, 2015. http://www.cetesb.sp.gov.br/agua/qualidade-da-agua-subt erranea/63-guarani.

[6] Ribeirão Preto. 2014. Region of Ribeirão Preto. Accessed November 6 , 2015. http://www.ribeiraopreto.sp.gov.br/crp/i71regiao.htm. 
[7] Guijt, I. M., and Moiseev, A. 2001. "Resource Kit for Sustainable Assessment.” IUCN, Gland, Switzerland and Cambridge, UK.

[8] Kronemberger, D. M. P., Carvalho, C. N., and Junior, J. C. 2012. "Sustainability Indicators in Small Hydrographic Basins: An Application of the Sustainability Barometer to the Jurumirim Basin (Angra dos Reis, Rio de Janeiro).” Geochimica Brasiliensis 18 (2): 86-98.

[9] Brazilian Institute of Geography and Statistics. 2014. Geosciences. Accessed September 5, 2015. http://www.ibge.gov.br/home/geociencias/recursosnaturai s/ids/ids2010.pdf.

[10] Kronemberger, D. M. P. 2003. “The Viability of Sustainable Development at the Local Scale: The Case of the Jurumirim Basin (Angra dos Reis, Rio de Janeiro).” Ph.D. final thesis, Rio de Janeiro: Institute of Chemistry Universidade Federal Fluminense.

[11] Kronemberger, D. M. P., Junior, J. C., Nascimento, J. D., Collares, J. E. R., and Silva, L. D. 2008. "Sustainable Development in Brazil: An Analysis Based on the Application of the Barometer of Sustainability.” Society and Nature 20 (1): 25-50. 